\title{
Effectiveness of erosion control measures along the Qinghai-Tibet highway, Tibetan plateau, China
}

\author{
Xianli $\mathrm{Xu}^{\mathrm{a}, \mathrm{b}}$, Keli Zhang ${ }^{\mathrm{c}, *}$, Yaping Kong ${ }^{\mathrm{d}}$, Jiding Chen ${ }^{\mathrm{d}}$, Bofu $\mathrm{Yu}^{\mathrm{e}}$ \\ ${ }^{a}$ State Key Laboratory of Systems Ecology, Research Center for Eco-Environmental Sciences, Chinese Academy of Sciences, \\ Beijing 100085, PR China \\ ${ }^{\mathrm{b}}$ Graduate University of the Chinese Academy of Sciences, Beijing 100039, PR China \\ ${ }^{c}$ School of Geography and Remote Sensing Sciences, Beijing Normal University, Beijing 100875, PR China \\ ${ }^{\mathrm{d}}$ Chinese Academy of Transportation Science, MOC, Beijing 100029, PR China \\ e School of Engineering, Griffith University, Nathan Qld 4111, Australia
}

\begin{abstract}
Severe runoff and water erosion can occur from road sideslopes. To investigate the magnitude of runoff and soil loss from road embankment and the effectiveness of a range of engineering and non-engineering erosion control measures, runoff and soil loss were measured along the Qinghai-Tibet highway near Tuotuo river in the summers of 2003 and 2004. The site is characterized by its high altitude, low summer rainfall and permanently poor vegetation cover. The results show that engineering measures can be effective in the short term, while re-vegetation of the road sideslopes is effective when the vegetation cover is established. A combination of lattice and re-vegetation is most effective overall.
\end{abstract}

(C) 2006 Elsevier Ltd. All rights reserved.

Keywords: Qinghai-Tibet highway; Erosion control

\section{Introduction}

With rapid economic development and growth, an extensive road network is being constructed in many regions of China. Road construction can create extensive surface disturbance with adverse impacts on surrounding environments, especially where the soil is highly susceptible to erosion, vegetation cover poor, and ecosystem fragile. These disturbances may include, but not limited to, removing the top soils, destroying native vegetation, sometimes altering natural topography, and resulting in severe surface runoff and water erosion. The sediments from the construction site can be delivered into streams and rivers, and become an important non-point pollution source for the receiving environment (Lane and Sheridan, 2002).

To effectively control erosion on road sideslopes and reduce its adverse impacts on watershed ecology, it is important to investigate the magnitude of runoff and soil loss and evaluate the effectiveness of erosion control

\footnotetext{
* Corresponding author.

E-mail address: kunqing@bnu.edu.cn (K.L. Zhang).
} 
measures. The focus has mostly been on slope stability to improve road safety in the past, less on ecological aspect of side slope design, although some of the engineering measures can reduce soil loss from road sideslopes (Yang et al., 2000; Luo, 2002). With increased awareness of environment protection, vegetation measures on road sideslopes have been widely applied. Many experiments showed that vegetation could be effective in controlling soil loss from road surfaces, road fill slopes and cut slopes (Grace, 2000; Fransen et al., 2001; Appelboom et al., 2002). Configuration of various plants and combination of different measures, and it was noted that the combination of engineering and vegetation measures could be effective in controlling soil loss (Xiao et al., 2004). In addition, to reduce the cost of construction and maintenance, and to protect the local ecosystem, Grace (2002) suggested that local species should be mainly used for erosion control. While serious erosion of side slopes has been widely recognized and investigated, these investigations of erosion control measures are, in most cases, specific to a particular region, using rainfall simulators mostly, and to our knowledge, no investigation into erosion control has been conducted under natural conditions on the Tibetan plateau.

The Tibetan plateau is known for its high altitude, unique geomorphology, and extremely severe weather conditions (Luo et al., 2004). It is the headwater region for many large rivers in China and Southeast Asia, e.g. the Yangtze, Yellow, and Mekong rivers. Road construction and maintenance are expensive and difficult in this region. In addition, the Qinghai-Tibet railway will be completed soon and erosion control along the railway will also become a critical issue.

\section{Methods}

The section of the Qinghai-Tibet highway from Gelmu in Qinghai province to Lhasa in Tibet autonomous region is $1137 \mathrm{~km}$ long with width of about $7 \mathrm{~m}$ and traverses several mountain ranges e.g. Kunlun mountain, Kekexili mountain, as well as many river basins e.g. Xieshui river, Chumaer river. At present, the QinghaiTibet highway is ranked as secondary highways in China. The highway is of importance for inter-provincial transportation in Tibet, and serves as a major delivery route for more than $85 \%$ of materials and $90 \%$ of passengers moving from and to the Tibet region. During the second-phase of the re-construction and improvement project, the roadbed was raised to reduce the effects of freeze-thaw on road stability. The erosion potential on road sideslopes is increased with this upgrade.

The experiment site is located $25 \mathrm{~km}$ South from the Tuotuo river meteorological station (Fig. 1), Qinghai, about $4553 \mathrm{~m}$ in elevation. The average annual precipitation is $272 \mathrm{~mm}$ at the Tuotuo river meteorological station, and about $85 \%$ of which occurs in June to September. Between 1971 and 1998, the maximum recorded daily precipitation was $50.2 \mathrm{~mm}$, and the average annual temperature was below $-5^{\circ} \mathrm{C}$. The site is located in the alpine grassland region, with low vegetation cover. The predominant grasses are cyperaceous and gramineous, i.e. Alpine Sagebrush (Kobresia pygmaea), Drooping Wildrye (Elymus natans), Speargrass (Splendid achnatherum), Alpine Rockjasmine (Androsace alpine). Soil texture is coarse and loose (Table 1) on the road sideslope, mostly sand and gravel.

An open area next to the highway was selected to install a Siphonal Automated Record Rain Gauge (SARRG) surrounded by wires to prevent exotic disturbances in June 2003. From the SARRG, rainfall amount and average rainfall intensity were measured and recorded for each runoff and soil loss event.

At the same time, natural runoff plots commonly used for soil erosion research on farmland were planted on the road sideslope. Each plot is $4 \mathrm{~m}$ long, $2 \mathrm{~m}$ wide and has a $30^{\circ}$ slope. These plots were enclosed with iron sheets vertically inserted into road sideslope. Fifteen plots were established for the trial (Fig. 2):

Control Plots: 2 Bare Plots (BP): no special measures.

Engineering Measures Plots (EMP): Runoff Interception \& Drainage Plot (IDP); Concrete Prefabricated Panes Plots (PPP); LAttice Plots (LAP).

Vegetation Measures Plots (VMP): 2 Common Seedling Plots (CSP); 2 Seedling with Off-site Soil Plots (SOSP). Common Seedling refers to direct application of seeds to the road sideslope without using any top soil. Seedling with Off-site Soil involves mixing the top soil with seeds and covering the road sideslope with the top soil for about $5 \mathrm{~cm}$. The top soil had been stockpiled during the road construction phase. In addition, an erosion plot was set up on a natural slope surface with an undisturbed native vegetation cover 

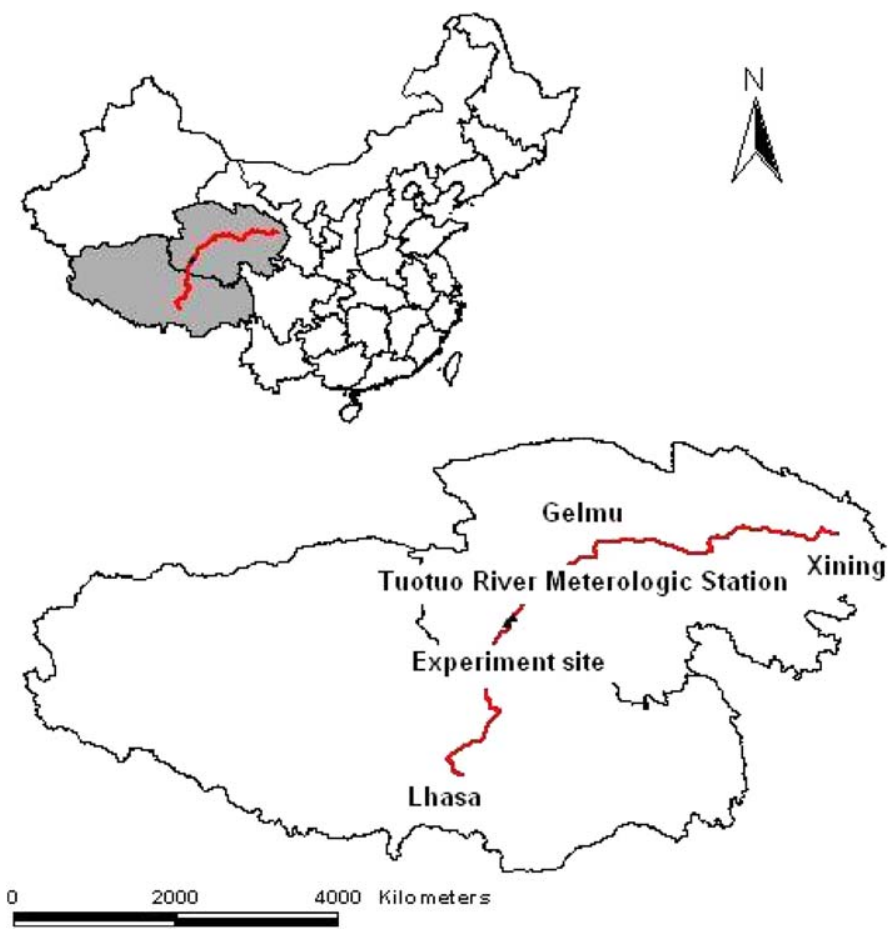

Fig. 1. Location of the experiment site.

Table 1

Soil properties on roadside slopes

\begin{tabular}{lllll}
\hline Sand & Silt & Clay & Organic matter & pH \\
\hline $2 \sim 0.05 \mathrm{~mm}$ & $0.05 \sim 0.002 \mathrm{~mm}$ & $<0.002 \mathrm{~mm}$ & $0.33 \%$ & 8.76 \\
$93.30 \%$ & $0.23 \%$ & $6.47 \%$ & & \\
\hline
\end{tabular}

$400 \mathrm{~m}$ away from the road (NVP), and this plot has the same physical dimension as others with the exception of a $20^{\circ}$ slope.

Combined Measures Plots: 2 Concrete Prefabricated Panes + Common Seedling Plots (PPCSP); 2 LAttice + Common Seedling Plots (LACSP).

Each plot has one trough connected between a plot and a runoff collection drum, $60 \mathrm{~cm}$ in diameter. When runoff occurred, water volume was firstly measured in the drum and runoff depth was calculated as water volume divided by horizontally projected plot area $\left(7.52 \mathrm{~m}^{2}\right.$ for the natural vegetation plot, $6.93 \mathrm{~m}^{2}$ for other treatments); secondly, the water in the drum was stirred and rapidly sampled, and the solid sediment weight was obtained by drying the samples (at $105^{\circ} \mathrm{C}$ ) in laboratory; lastly soil loss per unit area for each runoff event was determined using runoff volume, sediment concentration and projected plot area. The observation periods were August 4th-31st 2003 and June 21st-September 6th 2004.

Vegetation cover was assessed in the field, and vegetation body was sampled, dried and weighed separately in terms of its above ground and below ground biomass in August 2004. There was no vegetation survey in 2003.

To compare the effectiveness of different erosion control measures, an index of effectiveness (EI) is used:

$$
\mathrm{EI}=\frac{Y_{\mathrm{c}}-Y_{\mathrm{m}}}{Y_{\mathrm{c}}} \times 100 \%
$$



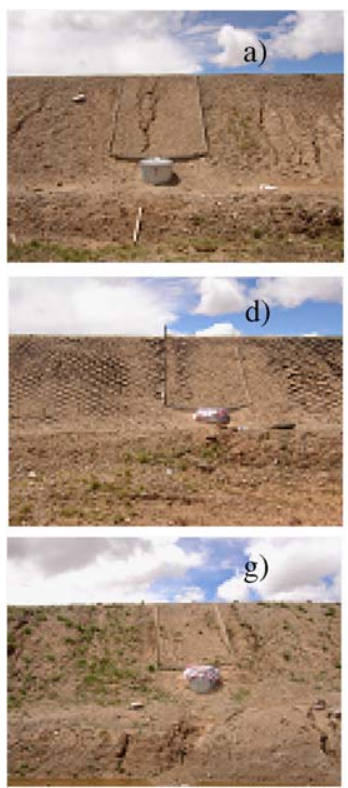

b)
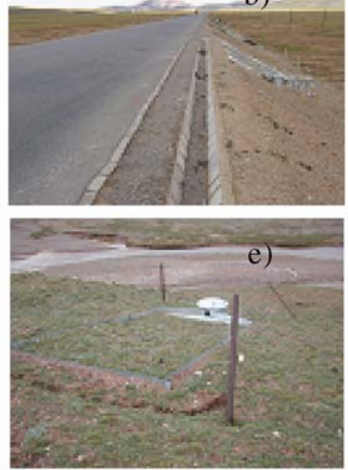

h)

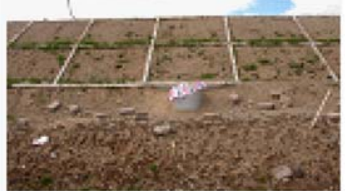

c)
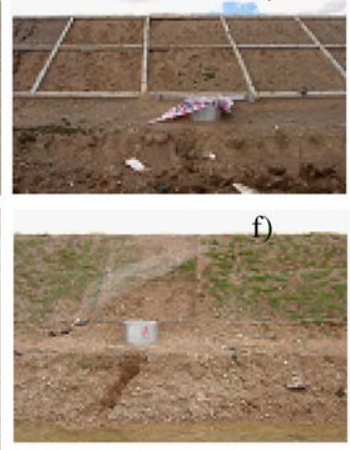

i)

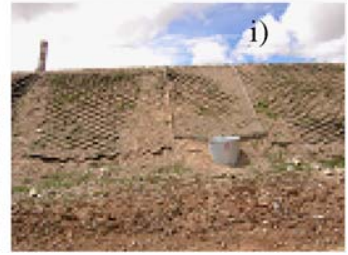

Fig. 2. Different erosion control measures taken in August 2004. (a) Control Plot; (b) Interception and Drainage Plot; (c) Prefabricated Panes Plot; (d) LAttice Plot; (e) Natural Vegetation Plot; (f) Seedling with Off-site Soil Plot; (g) Common Seedling Plot; (h) Prefabricated Panes + Common Seedling Plot; (i) LAttice + Common Seedling Plot.

where EI is the effectiveness index of the measure (\%); $Y_{\mathrm{c}}$ is the runoff depth $(\mathrm{mm})$ or soil loss (t/ha) from the control plot; $Y_{\mathrm{m}}$ is the runoff depth $(\mathrm{mm})$ or soil loss $(\mathrm{t} / \mathrm{ha})$ from the plots with erosion control measures.

\section{Results}

\subsection{Rainfall characteristics and soil erosion intensity}

The total rainfall amount in the first trial period was $93.2 \mathrm{~mm}$ in 2003 , and it was $226.7 \mathrm{~mm}$ in the second in 2004 (Table 2). Rainfall in August 2003 and August 2004 were 1.53 and 1.88 times higher than the average rainfall for August at the Tuotuo river meteorological station indicating that the study period embraced wetter conditions than the long-term average.

Based on the data for the 2 control plots (bare plots), from 13th June to 7th September, 2004, the average runoff was $0.444 \mathrm{~m}^{3}$, or $64.1 \mathrm{~mm}$ using the projected area of $6.93 \mathrm{~m}^{2}$. For the same period, the average soil loss from the control plots was $108.9 \mathrm{t} /$ ha from rainfall erosion alone (freeze and thaw erosion is not considered in this paper). The average runoff and soil loss from the control plots were $33.3 \mathrm{~mm}$ and $23.8 \mathrm{t} / \mathrm{ha}$, respectively, for the period in 2003. Soil loss during the period may be well above the long-term average as rainfall in August 2004 was higher than normal (Table 2).

Table 2

Rainfall (mm) during 4th-31st August 2003 and 21st June-6th September 2004

\begin{tabular}{llllll}
\hline & June & July & August & September & Total \\
\hline 2003 & - & - & 93.2 & - & 93.2 \\
2004 & 45.5 & 59.2 & 114.8 & 7.2 & 226.7 \\
Average $(1971-1998)^{\mathrm{a}}$ & 50 & 78 & 61 & 42 & 231 \\
\hline
\end{tabular}

\footnotetext{
a Tuotuo river meteorological station.
} 


\subsection{Effectiveness of different erosion control measures}

As seen in Fig. 3(a), the effectiveness in runoff reduction of IDPs and PPPs were $57.1 \%$ and 58.3\%, while LAttice Plot (LAP) was not particularly effective in the runoff reduction in the first year (2003). In 2004, all the three engineering measures were effective in reducing runoff with EI values between $40 \%$ and $60 \%$. As shown in Fig. 3(b), engineering measures reduce soil loss more effectively than they do runoff. IDP and PPP show consistent EI values of above $90 \%$ over the two years. EI value for soil loss reduction for LAP increased from $57.8 \%$ in 2003 to $89.2 \%$ in 2004 consistent with the increase in effectiveness in reducing runoff using this treatment.

In the LAttice Plot (Fig. 3(a) and (b)), the reason for the increase in the effectiveness over the two years may be related to the changes to the soil condition caused by lattice construction operations. In the first year (2003), the lattice was inserted into the side slope and this may have caused the soil compaction, and led to greater soil loss reduction than runoff reduction. In the second year, much of lattice was exposed due to water erosion in the first year, and could intercept more runoff and result in a greater soil loss reduction than before. This result implies that to maximize erosion control effectiveness, the lattice should not be completely covered with soil and other materials initially.

In addition, many rills were observed in the control plots, PPPs and LAPs (Fig. 2). They are wide in the upper and narrow in the lower section of the plot. There were no pronounced rills in the Interception and Drainage Plots because the water had been diverged away from the road surface. Therefore, it can be concluded that the road surface is also a source of runoff to initiate rill erosion on sideslopes if the runoff from road surface is not intercepted or diverged away appropriately. Once the road surface runoff is effectively controlled, the soil loss from sideslopes would be significantly reduced.

In general, the 3 engineering measures can effectively reduce soil loss from sideslopes, and may be appropriate for erosion control on the Tibetan Plateau. However, attention should be paid to the quality of these measures. Serious problems even damages can occur due to poor construction of these measures. For example, water leaking from poorly sealed cracks or holes, loose contact parts, poorly rammed structures, or runoff converging along a flow line, may all lead to severe scour on sideslopes with adverse impacts on the road embankment and the surrounding environment.

As shown in Fig. 4, all vegetation measures reduce soil loss as greatly as engineering measures, although they do not reduce the runoff to the extent as engineering measures do based on this set of experiments. The effectiveness of CSPs and SOSPs measures varied widely from year to year, while the Natural Vegetation plot shows a more consistent runoff and erosion pattern over time compared to the other two vegetation measures. Ground cover for all the vegetation measures was less than 35\% (Table 3). The low vegetation cover may be a key reason for the low EI values in terms of runoff reduction for the vegetation measures. It is worth

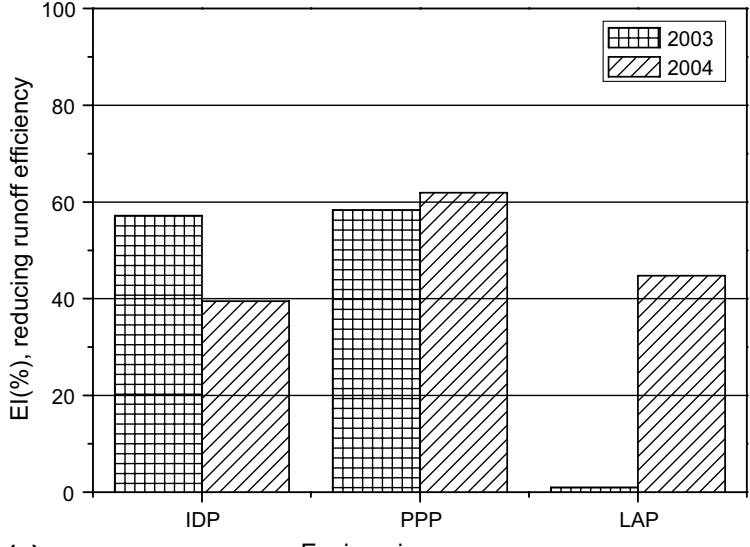

(a)
Engineering measures

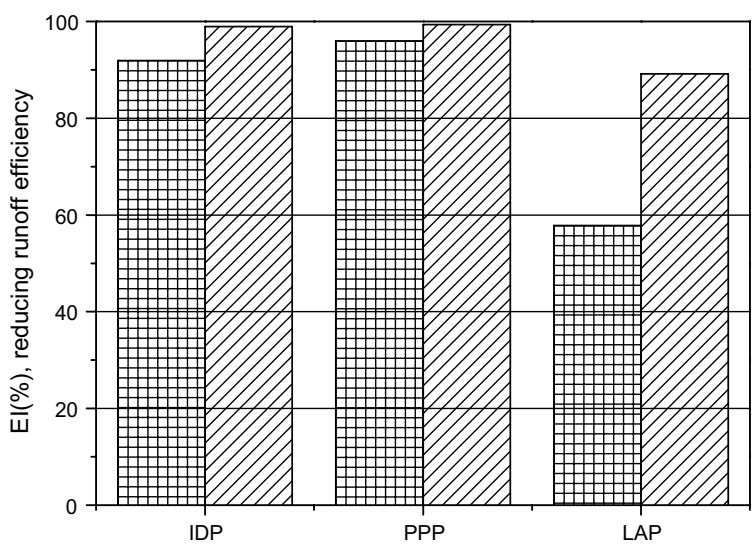

(b)

Engineering measures

Fig. 3. Effectiveness of engineering measures in (a) runoff reduction, (b) soil loss reduction. Notes: IDP - Interception and Drainage Plots; PPP - Prefabricated Panes Plots; LAP - LAttice Plots. 

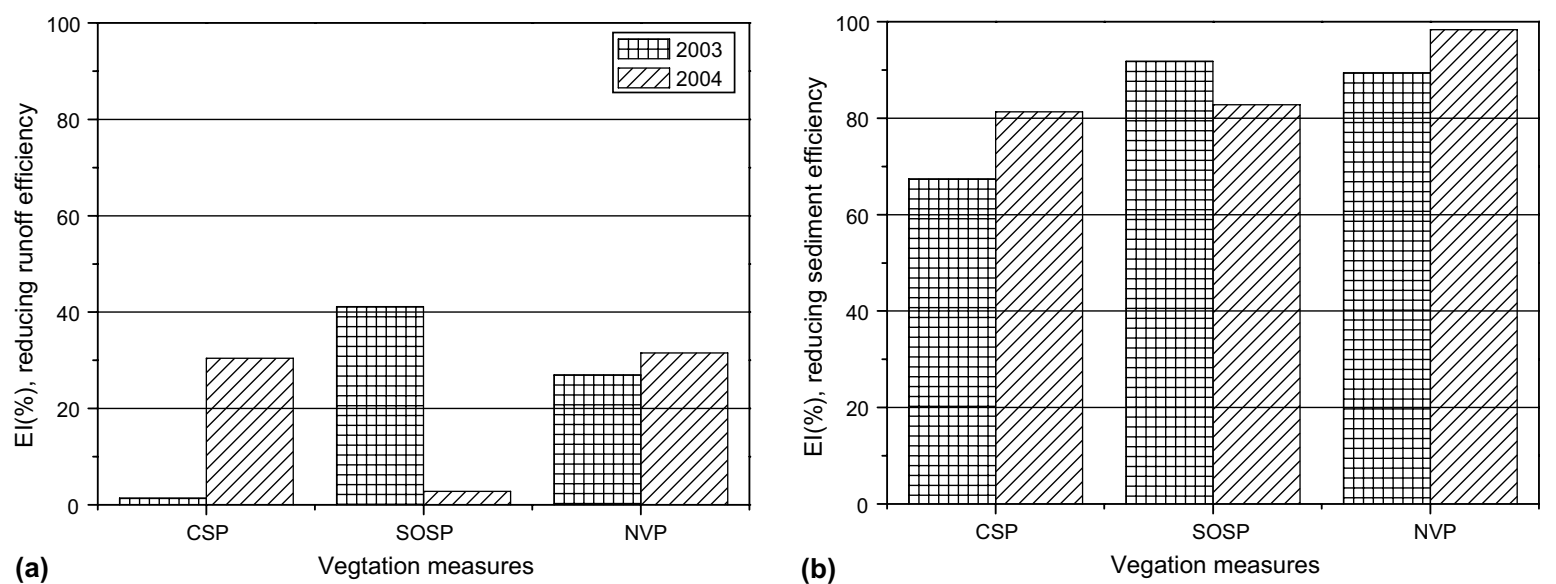

Fig. 4. Effectiveness of vegetation measures in (a) runoff reduction, and (b) soil loss reduction. Notes: CSP - Common Seedling Plots; SOSP - Seedling with Off-site Soil Plots; NVP - Natural Vegetation Plots.

Table 3

Vegetation characteristics and the effectiveness in soil loss reduction

\begin{tabular}{lllcr}
\hline Vegetation & Cover $(\%)$ & Above ground biomass $\left(\mathrm{g} / \mathrm{m}^{2}\right)$ & Below ground biomass $\left(\mathrm{g} / \mathrm{m}^{2}\right)$ & $\begin{array}{l}\text { EI }(\%) \text { for soil loss } \\
\text { reduction }\end{array}$ \\
\cline { 3 - 5 } & & & & 2003 \\
\hline Common seedling & 11.6 & 33.6 & 101.9 & 67.4 \\
Seedling with off-site soil & 25.4 & 28.8 & 106.1 & 81.3 \\
Natural vegetation & 31.7 & 38.1 & 192.0 & 82.8 \\
\hline
\end{tabular}

Vegetation cover, above and below ground biomass in August 2004.

noting that the low level of vegetation is still quite effective in reducing soil loss for all the vegetated sites. The relatively high below ground biomass may have led to a better soil structure, increased soil strength, hence the apparent reduction in soil erodibility. Importance of roots in controlling soil loss, especially in the initial stage of vegetation growth, has been widely noted (Gyssels et al., 2002; Gyssels and Poesen, 2003). EI values for the natural vegetation plot were above $90 \%$ with respect to soil loss reduction. This indicates that vegetation erosion control measures have great potential in reducing soil loss, especially when the cover is well established. From Table 1, the material on the side slope is relatively coarse and low in organic matter, thus the grass did not grow well on Common Seedling Plots and this treatment has by far the lowest vegetation cover of the three vegetation measures. Table 3 shows that the SOSP treatment greatly improves the soil condition, and create a more favorable condition for vegetation growth. Therefore, the SOSP measure is most effective for sideslope erosion control.

The effectiveness indexes for the combined measures are shown in Fig. 5(a) and (b). The two combinations of engineering and vegetation measures have considerable effect on runoff reduction (at least $37 \%$ ) and soil loss reduction of above $97 \%$. Typically, at the early stage of the trial, the engineering measures can intercept runoff and eroded sediment, and increase water, soil, nutrients and seeds retention, thus accelerate the establishment of an effective vegetation cover. With vegetation growth, the canopy can further intercept rainfall, and reduce the direct impact of rain drops on the soil surface. The root system can strengthen the soil and reduce its erodibility. Therefore, a combination of engineering and vegetation measures can effectively control erosion at the site.

The vegetation is well distributed in the LAttice + VMPs with an average cover of $9.6 \%$, and almost every lattice has vegetation (Fig. 2). In PPPs + VMPs, vegetation is patchy, and most of it is distributed along the center-line of the plots across panes with an average cover of $5.1 \%$ (Fig. 2). Although the soil loss control effectiveness of the PPPs + VMPs are relatively high, the overall outcome may not be as desirable as the LAP + VMP measure if vegetation distribution is taken into account in the context of landscape ecology. 

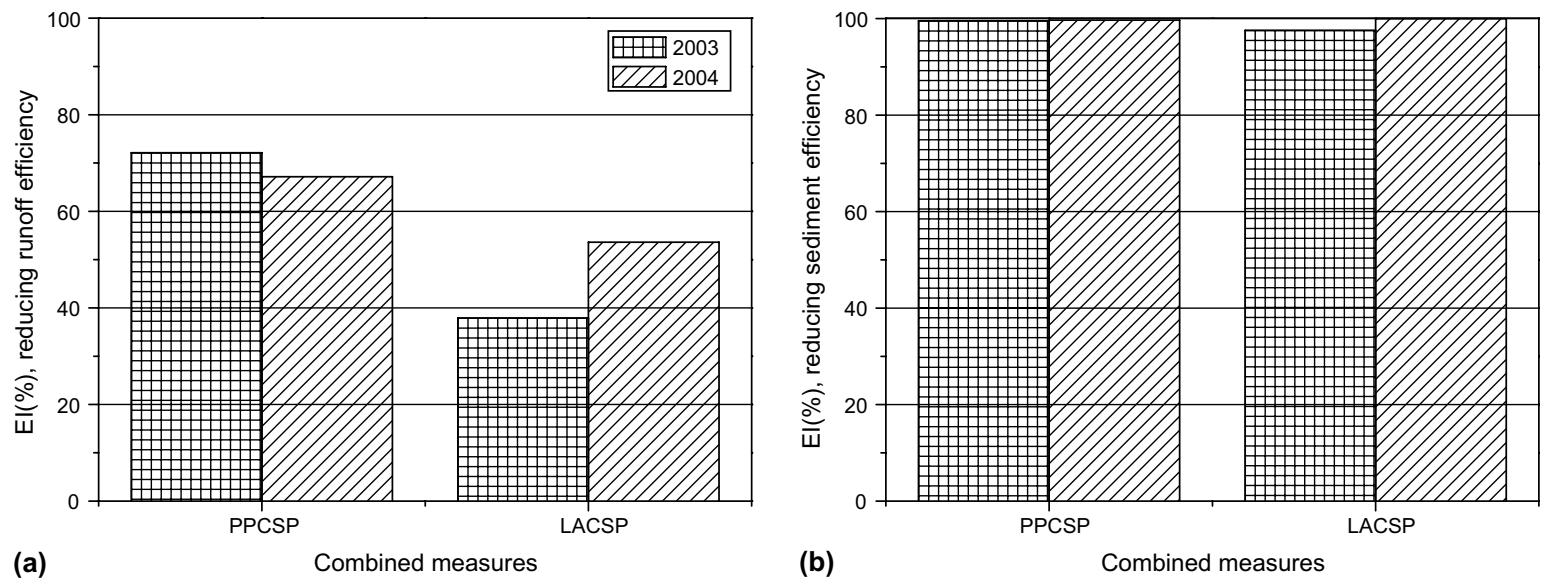

Fig. 5. Effectiveness of combined measures in (a) runoff reduction, and (b) soil loss reduction. Notes: PPCSP - Prefabricated Panes + Common Seedling Plots; LACSP - LAttice + Common Seedling Plots.

As shown in Fig. 6(a), an overall comparison of the 4 groups of measures in reducing runoff indicates that all 4 measures can reduce runoff, and the Combined Measure is the most effective of the 4 groups, and the rest, in a descending order, are EMP, NVP, and VMP. In addition, the effectiveness of all measures was relatively consistent over the two years, and the effects on runoff reduction were only slightly greater in the second year than the first for all the measures except the planted vegetation. For the VMP, one of the reasons why the effectiveness in terms of runoff reduction decreased over the two years is that much of perennial vegetation was not well established enough to go through the cold winter and died before the second summer season had arrived. The outcome may have been more favorable had the grass been seeded earlier in 2003; the actual seeding date was sometime in June 2003.

Although the effects on runoff were comparatively low, all measures showed good outcomes for controlling soil loss (Fig. 6(b)). The combined measure is again the most effective, followed by NVPs, EMPs, and lastly VMP. The EI values range from $80 \%$ to $99 \%$ in the first year, and $82 \%$ to $99 \%$ in the second. The EI value for erosion control shows an increasing trend with time for all treatments (Fig. 6(b)). The EI value was increased from $89 \%$ to $98 \%$ for the natural vegetation plot over the two years. This is by far the largest increase of the 4 groups of treatments. After one-year enclosure to prevent grazing and other disturbances, the vegetation in the natural vegetation plot was well recovered, and the capability to control soil loss increased. The low soil loss
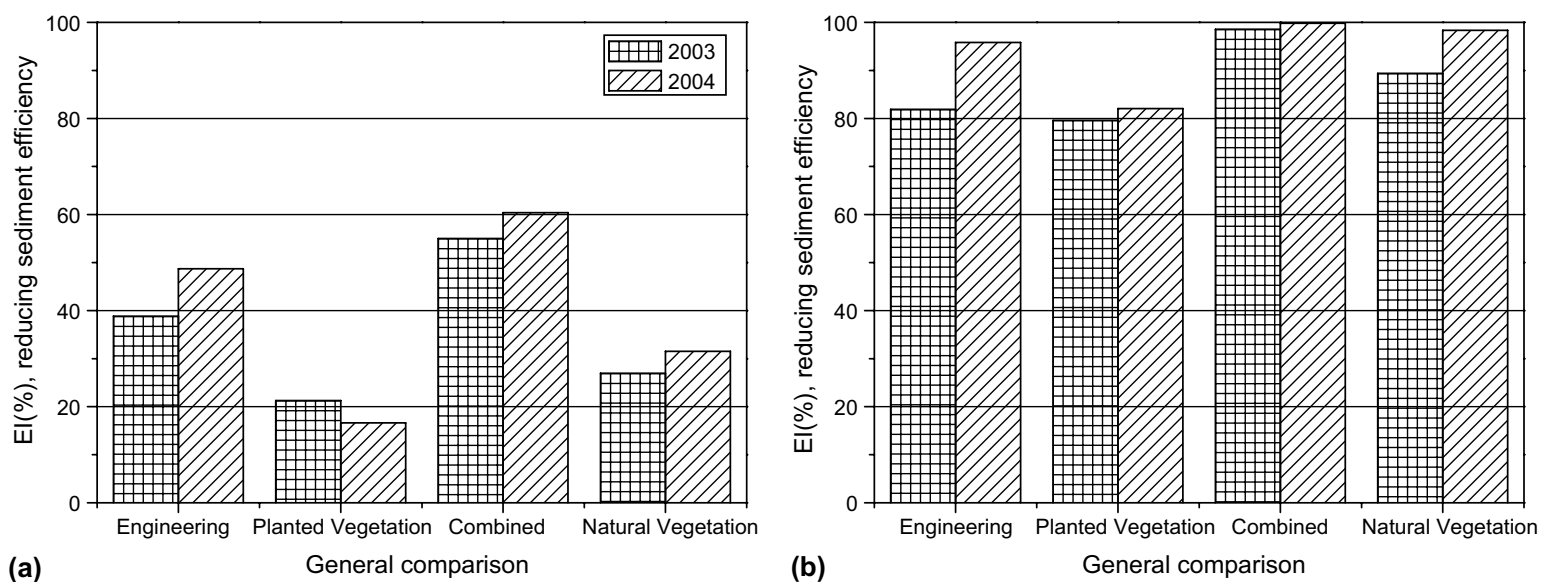

Fig. 6. The overall effectiveness of different types of erosion control measures in (a) runoff reduction and (b) soil loss reduction. 
from the natural vegetation plot would suggest that the VMP should have great potential to control soil loss in the longer term when the vegetation cover is well developed.

\section{Conclusions}

This study shows that engineering measures such as Prefabricated Panes, LAttice, and Interception and Drainage can reduce runoff and soil loss from road sideslopes along the Qinghai-Tibet highway. Vegetation measures are effective for erosion control, although the reduction in runoff is not as great as other measures considered in this paper, in part due to the poor growth of the plants in this harsh environment. With an increase in vegetation cover, the effectiveness of vegetation measures would improve over time. Use of top soil is important for regeneration of vegetation on road sideslopes. Re-vegetation without engineering measures takes time. In the longer term, vegetation measures have the potential to reduce runoff and soil erosion substantially when the vegetation cover is well established. The combined engineering and vegetation measure showed considerable and consistent effectiveness in reducing runoff and soil loss. Of these combined measures, the LAttice + Common seedling measure showed its capacity for water retention, reduced loss of soil and seeds, and better vegetation growth potential. The combined measure has the benefit of runoff and erosion control on the short- and long-term basis.

\section{Acknowledgements}

This research was funded by the Ministry of Communications of China (Communication Development Project in western China, Grant no. 200231822107) and the Natural Science Foundation of China (Grant no. 40271072). We are also grateful to Peng Wang and Jiafu Li from Chinese Academy of Transportation Science for their fieldwork. Constructive comments by two anonymous reviewers are gratefully acknowledged.

\section{References}

Appelboom, T.W., Chescheir, G.M., Skaggs, R.W., Hesterberg, D.L., 2002. Management practices for sediment reduction from forest roads in the coastal plains. Transactions of the American Society of Agricultural Engineers 45 (2), 337-344.

Fransen, P.J.B., Phillips, C.J., Fahey, B.D., 2001. Forest road erosion in New Zealand: Overview. Earth Surface Processes and Landforms 26, 165-174.

Grace III, J.M., 2000. Forest road sideslopes and soil conservation techniques. Journal of Soil and Water Conservation 55 (1), 96-101.

Grace III, J.M., 2002. Effectiveness of vegetation in erosion control from forest road sideslopes. Transactions of the American Society of Agricultural Engineers 45 (3), 681-685.

Gyssels, G., Poesen, J., 2003. The importance of plant root characteristics in controlling concentrated flow erosion rates. Earth Surface Processes and Landforms 28, 371-384.

Gyssels, G., Poesen, J., Nachtergaele, J., Govers, G., 2002. The impact of sowing density of small grains on rill and ephemeral gully erosion in concentrated flow zones. Soil \& Tillage Research 64, 189-201.

Lane, P.N., Sheridan, G.J., 2002. Impact of an unsealed forest road stream crossing: water quality and sediment sources. Hydrological Processes 16, 2599-2612.

Luo, F.T., 2002. Application of anchor technology in highway construction. Journal of Soil and Water Conservation 16 (5), 146-148, in chinese.

Luo, L., Zhang, K., Kong, Y., Chen, J., 2004. Temporal and spatial distribution of soil loss on Tibet-Qing Plateau. Journal of Soil and Water Conservation 18 (1), 58-62, in chinese.

Xiao, P.Q., Shi, X.J., Chen, J.N., 2004. Experimental study on protecting speedway slope under rainfall and flow scouring. Journal of Soil and Water Conservation 24 (1), 16-18, in chinese.

Yang, X.T., Dong, H.Y., Huang, Y.R., 2000. Study on slope stability of expressway in Loess Region. Journal of Soil and Water Conservation 14 (1), 77-81, in chinese. 